\title{
Rheumatoid disease presenting as a nephrotic syndrome
}

\author{
C D SHORT, ${ }^{1}$ L R SOLOMON ${ }^{1}$ N P MALLICK, ${ }^{1}$ AND J D MACKAY \\ From the ${ }^{1}$ Department of Renal Medicine, Manchester Royal Infirmary, Oxford Road, Manchester; and the \\ ${ }^{2}$ Department of Medicine, Victoria Hospital, Blackpool
} syndrome. Renal biopsy showed a membranous glomerulopathy and coincident investigationshowed high serum titres of rheumatoid factors. It was not until some months later that he्w developed articular and extra-articular manifestations of rheumatoid arthritis.

Key words: membranous glomerulonephritis.

The association between the development of a nephrotic syndrome secondary to membranous nephropathy in patients with rheumatoid arthritis (RA) and treatment with gold or penicillamine is well established, ${ }^{12}$ but reports of patients with RA developing membranous nephropathy in the absence of such treatment are few, ${ }^{3}$ and in all the arthropathy preceded evidence of nephropathy.

We report a patient who presented with a nephrotic syndrome due to membranous nephropathy proved by biopsy and within months developed features fully consistent with a diagnosis of rheumatoid arthritis.

\section{Case report}

In June 1985 a 62 year old retired maintenance foreman presented with swelling of his legs and was found to have a nephrotic syndrome. Blood pressure was $160 / 95 \mathrm{mmHg}$. He had experienced mild Raynaud's phenomenon for several years but with no arthritic symptoms or rashes and had not received gold, penicillamine, non-steroidal antiinflammatory drugs, or other agents associated with glomerular disease and had no other significant past medical history.

Accepted for publication 7 September 1987.

Correspondence to Dr C D Short, Department of Renal Medicine, Manchester Royal Infirmary, Oxford Road, Manchester M13 9WL.

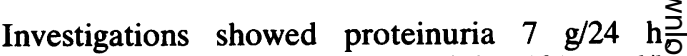
plasma albumin $16 \mathrm{~g} / \mathrm{l}$, plasma creatinine $101 \mu \mathrm{mol} / \mathrm{I}_{\%}$ creatinine clearance $65 \mathrm{ml} / \mathrm{min}$, Wasserman reactions negative, hepatitis B surface antigen not detected $\underset{\vec{F}}{\overrightarrow{2}}$ antinuclear factor (ANF) negative, anti-DNA anti윽 bodies negative, fasting blood sugar $4.7 \mathrm{mmol} / \mathrm{l}$, and there was no increase in urinary free light chains. sheep cell agglutination test (SCAT) and latex tes. for rheumatoid factor were strongly positive at $>25 \%$ IU and $>64$ IU respectively.

Percutaneous renal biopsy showed the charac teristic changes of membranous nephropathy with thickening of the peripheral capillary basemen membranes and subepithelial spikes in the absence of increased cellularity. Immunofluorescent studies demonstrated IgG, C3, and C1q only, deposited in diffuse, global, and granular fashion along the glomerular basement membranes.

He was treated initially with a high protein, higl calorie, low sodium diet, and conventional diuretie agents. When the histological diagnosis was made treatment was started with prednisolone $100 \mathrm{mg}$ orally on alternate days; proteinuria fell to less thare $1 \mathrm{~g} / 24 \mathrm{~h}$ within six weeks, plasma albumin rose to $29 \mathrm{~g} / \mathrm{l}$, and creatinine clearance remained stable.0 Three months after prednisolone was started, whicle by then had been reduced to $10 \mathrm{mg}$ on alternats days, he developed stiff and painful joints of hid hands, ankles, and shoulders. The symptoms were worse in the morning and lessened during the day 
Physical examination showed diffuse fusiform swelling of all fingers and tenderness of the wrists. SCAT and latex tests remained strongly positive, ANF and anti-DNA antibodies were negative repeatedly, and C3 and C4 levels remained normal. Radiographs of knees, hands, and shoulders showed no evidence of erosive arthropathy, but periarticular osteoporosis of the metacarpophalangeal and proximal interphalangeal joints was noted. Prednisolone dosage was increased to $15 \mathrm{mg}$ orally daily, and chloroquine $250 \mathrm{mg}$ orally daily was added, with some symptomatic improvement. He subsequently developed a peripheral neuropathy and cutaneous vasculitis, which required treatment with cyclophosphamide.

\section{Discussion}

This patient, with no evidence of systemic lupus erythematosus or other systemic disease associated with membranous nephropathy, infection, malignancy, or drug exposure, presented with a nephrotic syndrome due to membranous nephropathy (proved by biopsy) in the presence of strongly positive rheumatoid factor. Over the course of the next few weeks he developed the clinical features typical of RA.

Some studies suggest that membranous nephropathy only develops in patients with RA who are exposed to gold or penicillamine. ${ }^{4}$ This view is not held universally, however, ${ }^{5}$ and we believe that our patient provides further evidence to support the hypothesis that membranous nephropathy can develop independently of treatment in patients with RA.

The presentation of RA with such extra-articular manifestations as an isolated pleural effusion is well recognised, yet in all previous reports of membranous nephropathy in patients with RA without gold or penicillamine exposure the arthropathy had been manifest before the nephropathy. ${ }^{3}$ We suggest that in our patient a nephrotic syndrome was the extraarticular presenting feature, an observation not previously reported, with the articular features becoming overt subsequently.

\section{References}

1 Silverberg D S, Kidd E G, Shnitka T K, Ulan R A. Gold nephropathy: a clinical and pathologic study. Arthritis Rheum 1970; 13: 812-25.

2 Bacon P A, Tribe C R, Mackenzie J C, Verrier-Jones J, Cumming R H, Amer B. Penicillamine nephropathy in rheumatoid arthritis. $Q J$ Med 1976; 45: 661-84.

3 Honkanen E, Tornroth T, Pettersson E, Skrifvars B. Membranous glomerulonephritis in rheumatoid arthritis not related to gold or D-penicillamine therapy: a report of four cases and a review of the literature. Clin Nephrol 1987; 27: 87-93.

4 Sellars L, Siamopoulos K, Wilkinson R, Leohapand T, Morley A R. Renal biopsy appearances in rheumatoid disease. Clin Nephrol 1983; 20: 114-20.

5 Samuels B, Lee J C, Englemann E P, Hopper J. Membranous nephropathy in patients with rheumatoid arthritis: relationship to gold therapy. Medicine (Baltimore) 1978; 57: 319-27. 